\section{Pitiriasis rosada: un exantema que debe ser reconocido por el médico de primer contacto. Estudio de 30}

\section{casos}

\section{RESUMEN}

Antecedentes: la pitiriasis rosada es un exantema agudo diseminado de etiología desconocida y duración prolongada. Se caracteriza por placas eritematosas con un collarete de escama periférica. Aunque el cuadro clínico es aparatoso para el paciente y el familiar, la pitiriasis rosada es involutiva y generalmente remite sin secuelas. Frecuentemente es confundida con micosis y se prescriben tratamientos innecesarios.

Objetivo: describir las características clínicas y demográficas de la pitiriasis rosada en un grupo de pacientes pediátricos mexicanos.

Pacientes y métodos: estudio retrospectivo y descriptivo en el que se analizaron las características clínicas y demográficas de los pacientes evaluados en el Servicio de Dermatología del Instituto Nacional de Pediatría con diagnóstico de pitiriasis rosada en un periodo de 10 años.

Resultados: se encontraron treinta pacientes con pitiriasis rosada para una frecuencia de 3.6 por cada 1000 pacientes dermatológicos. Predominio en mujeres con una relación de 1.5:1 y edad promedio de 10 años. En más de la mitad de los casos (56\%) se observaron formas atípicas que hicieron necesaria la toma de biopsia en 7 pacientes para establecer el diagnóstico definitivo.

Conclusiones: el conocimiento de las características clínicas de la pitiriasis rosada, por médicos de primer contacto, evitará tratamientos y exámenes innecesarios.

Palabras clave: pitiriasis rosada, exantema, medallón heráldico.
Igor López-Carrera ${ }^{1}$ Carola Durán-McKinster ${ }^{2}$ María del Mar Sáez-de-Ocariz ${ }^{3}$ Luz Orozco-Covarrubias ${ }^{3}$ Carolina Palacios-López ${ }^{3}$ Ramón Ruiz-Maldonado ${ }^{4}$

${ }^{1}$ Residente de Dermatología Pediátrica.

2 Jefe del Servicio.

${ }^{3}$ Médico adscrito.

${ }^{4}$ Investigador emérito.

Servicio de Dermatología, Instituto Nacional de Pediatría, México.

\section{Pityriasis Rosea: A rash that should be recognized by the primary care physician. Study of 30 cases}

\section{ABSTRACT}

Background: Pityriasis rosea is an acute disseminated rash of unknown etiology and prolonged duration, characterized by erythematoussquamous plaques. Despite having an ostentatious clinical picture for both the patient and family, it is self-limited and usually resolves without sequelae. Pityriasis rosea is often erroneously diagnosed as mycosis and given unnecessary treatment.
Recibido: 2 de abril 2013

Aceptado: 19 de mayo 2014

Correspondencia: Dr. Ramón Ruiz Maldonado Instituto Nacional de Pediatría Servicio de Dermatología Insurgentes sur 3700-C CP. 04530 México, D.F. Tel. 10845528

Este artículo debe citarse como López-Carrera I, Durán-McKinster C, Sáez-de-Ocariz MM, Orozco-Covarrubias L, Palacios-López C, RuizMaldonado R. Pitiriasis rosada: un exantema que debe ser reconocido por el médico de primer contacto. Estudio de 30 casos. Acta Pediat Mex 2014;35:289-294. 
Objective: To describe the clinical and demographical features of pityriasis rosea in a group of Mexican pediatric patients.

Patients and methods: Retrospective and descriptive study in which the clinical and demographic features of patients attended at the department of dermatology of the National Institute of Pediatrics with diagnosis of pityriasis rosea within a ten year period were analysed.

Results: Thirty patients with pityriasis rosea, with a frequency of 3.6 per 1000 dermatological patients. Pityriasis rosea was more frequent in females with a ratio of 1.5 to 1 and a mean age of 10 years. More than half of the patients (56\%) had an atypical presentation, and biopsy was mandatory in 7 patients to establish the final diagnosis.

Conclusions: The knowledge of the clinical features of pityriasis rosea by primary care physicians will prevent from unnecessary work-up and treatments.

Keywords: pityriasis rosea, exanthema, herald patch.

\section{ANTECEDENTES}

La pitiriasis rosada fue descrita por el médico francés Camile Gibert en 1860; sin embargo, hay descripciones someras desde 1798 por Robert Willan, como lo refiere Percival Pott, ${ }^{1}$ que sirvieron de base para la descripción completa. Un estudio en adultos con pitiriasis rosada en Minnesota reveló que sólo en $43 \%$ de los casos hizo el diagnóstico un médico general o un médico internista. ${ }^{2}$ En la edad pediátrica no hay estudios que revelen el porcentaje de diagnósticos realizados por el pediatra.

La pitiriasis rosada es una entidad de etiología desconocida, probablemente de origen infeccioso, sin que se haya podido demostrar. Tiene una topografía y una lesión inicial muy características, lo cual es de mucha utilidad para sospechar el diagnóstico. ${ }^{1}$

\section{Epidemiología}

Aproximadamente $75 \%$ de los casos de pitiriasis rosada se observan entre los diez y los 35 años de edad. Ambos géneros se ven afectados en proporciones similares ${ }^{3}$ con ligero predominio del femenino. ${ }^{4}$ Se ha reportado una frecuencia de $2 \%$ en la consulta dermatológica. ${ }^{5}$

La incidencia en lactantes menores de dos años se ha reportado entre 0.1 y $0.3 \%,{ }^{6}$ mientras que en pacientes escolares menores de 10 años se presenta entre 6 y $10.5 \% .5,7$

\section{Etiología}

A pesar de que la causa de la pitiriasis rosada aún se desconoce, existen factores clínicos que sugieren un origen infeccioso, como lo es el hecho de que generalmente se presenta una vez en la vida (excepcionalmente dos veces). En la literatura especializada se reportó el caso de una niña de 8 años que presentó cuatro episodios con periodicidad anual, ${ }^{6}$ lo que sugiere una respuesta inmunológica. Además, en alrededor de $70 \%$ de los casos existen pródromos de infección en vías aéreas superiores y tiene mayor incidencia estacional en otoño, invierno y primavera. ${ }^{4}$ 
Respecto al agente causal, hay informes aislados que la asocian con virus HHV-6, HHV- $7^{4,7,8}$ y $\mathrm{HHV}-8^{8}$, así como con virus de influenza novel H1N1. ${ }^{9}$ Otros autores reportan posibles orígenes bacterianos por Chlamydia pneumoniae, Legionella pneumophila y Mycoplasma pneumoniae, aunque los estudios no han demostrado elevación de los títulos de anticuerpos en estos pacientes. ${ }^{10}$

\section{CUADRO CLÍNICO}

Existen dos formas de presentación de la pitiriasis rosada. La forma clásica tiene topografía y morfología características y la forma atípica puede presentar lesiones con diferentes distribución, morfología, o ambas. La forma clásica o típica se observa en la mayoría de los casos (hasta en 94\%). ${ }^{4,11}$ Las lesiones se localizan en tronco (Figura 1) y en el tercio superior de las extremidades; la forma atípica no se presenta en el tronco y predomina en las extremidades (Figura 2), por lo que se le ha denominado invertida.

En ocasiones, el cuadro inicia con pródromos de una infección de las vías aéreas superiores,

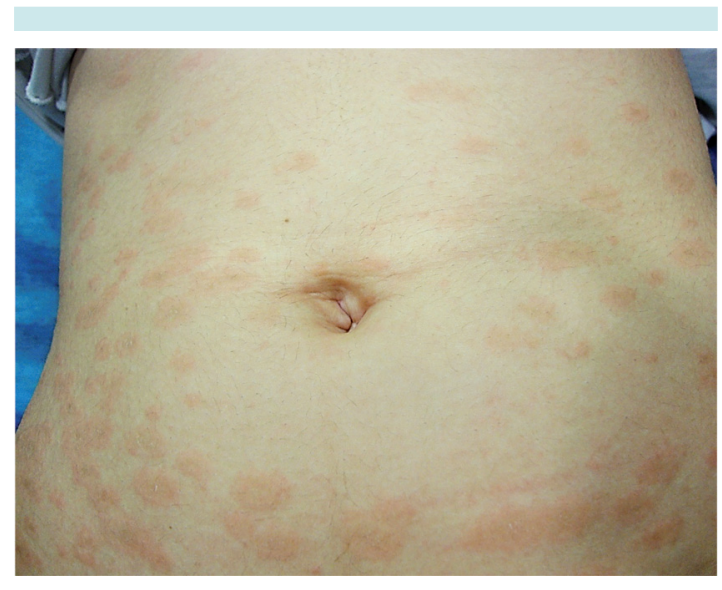

Figura 1. Forma típica de pitiriasis rosada. Múltiples placas redondas u ovales, de color rosado y descamación fina.

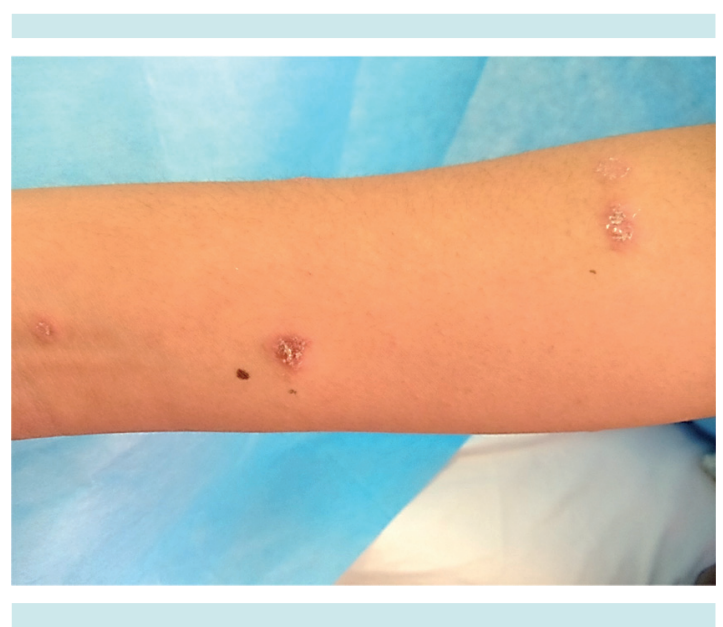

Figura 2. Pitiriasis rosada atípica. Las lesiones se localizan principalmente en extremidades y respeta el tronco.

seguidos de una placa eritematosa redondeada u ovalada con descamación fina en la periferia, de 2 a $3 \mathrm{~cm}$ de diámetro, que se localiza en el tronco en la mitad de los casos. ${ }^{12} \mathrm{~A}$ dicha placa se le ha denominado "medallón heráldico"7 (Figura 3) y permanece aislada aproximadamente de ocho a diez días; posteriormente, aparecen de forma súbita múltiples lesiones de menor tamaño, de color rosa pálido con un collarete de descamación fina (Figura 4). La cara generalmente permanece sin lesiones; ${ }^{2}$ éstas son escasas y pequeñas en piel cabelluda y cuello. Las marcas del tronco posterior aparecen a lo largo de las líneas de clivaje o de Langer (que corresponden a las líneas de tensión de la piel), son líneas inclinadas y parten de la línea central del tronco semejando la forma en que se disponen las ramas del "árbol de Navidad". ${ }^{13}$ En pacientes de piel blanca las placas se ven de color rosado, mientras que en piel morena sólo el borde es eritematoso y el centro claro. La mucosa oral rara vez se ve afectada, pero ocasionalmente puede haber úlceras en lengua y paladar, pápulas y placas anulares o máculas hemorrágicas. Estas lesiones son frecuentemente asintomáticas y, en la mayoría de casos, no se describen. ${ }^{14}$ 


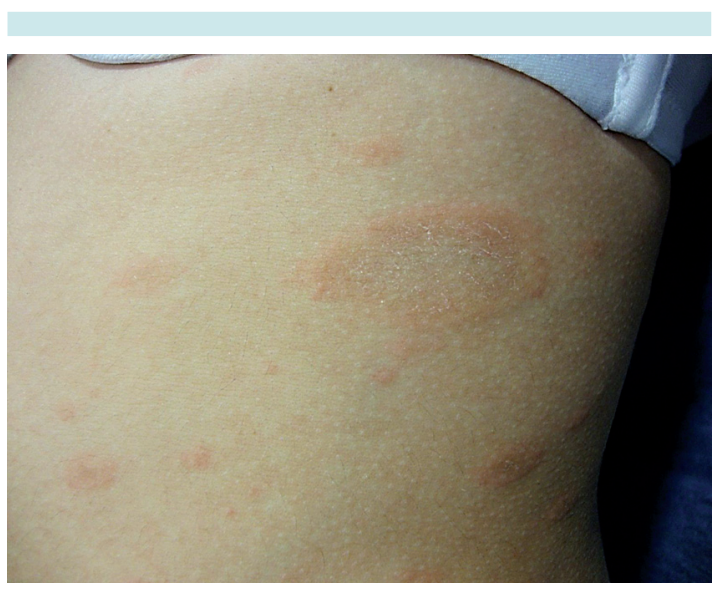

Figura 3. El "medallón heráldico" es la placa eritematoescamosa de mayor tamaño que aparece 10 a 15 días antes que las circundantes.

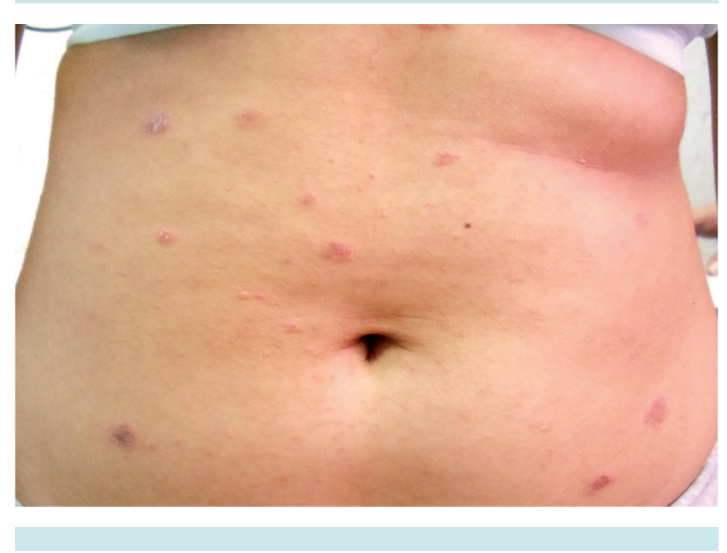

Figura 4. Múltiples placas redondas u ovales, eritematosas, con descamación fina.

La pitiriasis rosada se acompaña de mínimos síntomas constitucionales y desaparece espontáneamente de cuatro a ocho semanas en $80 \%$ de los pacientes; ${ }^{4}$ sin embargo, hay informes de casos que se prolongan hasta 6 meses. ${ }^{7}$ Las recaídas varían de un 1.8 a un $3.7 \% .^{7,12}$ El prurito usualmente es mínimo o no se presenta. ${ }^{4}$

\section{Patología}

Rara vez se indica la biopsia de piel debido a que los datos no son patognomónicos. ${ }^{7}$ La epidermis muestra hiperplasia leve con paraqueratosis focal, diminución o ausencia de la capa granulosa y espongiosis. También se observa extravasación de eritrocitos en dermis papilar y un infiltrado linfocítico en dermis superficial y alrededor de los vasos con exocitosis. En las lesiones menos recientes se encuentran eosinófilos. ${ }^{4,7}$ El medallón heráldico presenta hallazgos similares y un infiltrado perivascular superficial y profundo, menos espongiosis y más hiperplasia epidérmica. ${ }^{15}$

\section{DIAGNÓSTICO}

Es básicamente clínico; se sospecha por el antecedente de una lesión única seguida de la aparición brusca del resto de las placas, con o sin síntomas prodrómicos. ${ }^{4}$ Los exámenes de laboratorio no muestran alteraciones, por lo que no son necesarios.

\section{Diagnóstico diferencial}

Debe hacerse con todas las dermatosis que cursan con placas anulares y descamación fina. La tiña del cuerpo presenta una placa anular con el borde eritematoso y el centro más claro con descamación fina en la periferia, que se asemeja mucho al "medallón heráldico"; sin embargo, en la tiña el prurito es intenso y el crecimiento de la placa anular es rápido, mientras que en la pitiriasis rosada la placa es poco pruriginosa y permanece del mismo tamaño.

El eccema numular, una forma atípica de la dermatitis atópica, se caracteriza por placas ovaladas o redondas cubiertas de costras serohemáticas y descamativas pruriginosas; la sífilis secundaria debe sospecharse en pacientes sexualmente activos que presenten placas anulares pequeñas con descamación fina en el cuerpo, palmas y plantas. ${ }^{4,16}$

\section{Tratamiento}

El tratamiento de la pitiriasis rosada es sintomático dado que no existe uno que haya sido 
eficaz en general. Según estudios de medicina basada en evidencia y la revisión de la literatura por Cochrane ${ }^{7,17}$ los esteroides tópicos y los antihistamínicos orales no se recomiendan porque no han demostrado resultados. La lubricación frecuente reduce el prurito y el baño debe ser con jabón suave para evitar más resequedad y sin tallar la piel. La duración del cuadro puede disminuir con el uso de eritromicina por vía oral cuando se administra en la primera semana del exantema diseminado, disminuyendo el tiempo de evolución que se resuelve, en $73 \%$ de los casos, en dos semanas. ${ }^{18}$

Es recomendable que el paciente evite la exposición directa al sol en el sitio de las lesiones porque la escama de la placa evitará el bronceado y dejará una mancha hipocrómica en su lugar, aunque ésta es temporal y se resuelve espontáneamente es muy notoria en niños de piel morena.

\section{METODOLOGÍA}

Se hizo una revisión retrospectiva de los expedientes de pacientes de la consulta externa del Servicio de Dermatología del Instituto Nacional de Pediatría, en un periodo de diez años, entre enero de 2002 y diciembre de 2011, de los que se incluyeron 30 pacientes diagnosticados con pitiriasis rosada en el Servicio de Dermatología.

\section{Criterios de inclusión}

Pacientes de ambos géneros, en edad pediátrica, diagnosticados con pitiriasis rosada en el Servicio de Dermatología del Instituto Nacional de Pediatría de enero de 2002 a diciembre de 2011.

\section{Criterios de exclusión}

Pacientes que no cumplían con los criterios diagnósticos de la pitiriasis rosada.

\section{RESULTADOS}

Se incluyeron 30 pacientes con pitiriasis rosada estudiados en el Servicio de Dermatología del Instituto Nacional de Pediatría. La frecuencia de presentación fue de 3.6 por cada 1000 pacientes dermatológicos. Dieciocho pacientes fueron del género femenino y 12 del masculino. La edad estuvo comprendida entre 4 y 16 años, con un promedio de 10.3 años. El antecedente de infección de vías aéreas superiores se reportó en dos pacientes. El $66.7 \%$ de los casos tuvo el exantema en otoño e invierno. Ninguno presentó recurrencia del cuadro en el período de estudio.

Clínicamente encontramos las siguientes características: el "medallón heráldico" o lesión única inicial se detectó en 50\% de los pacientes o fue referido por un familiar; una cuarta parte de los pacientes refirió prurito leve o moderado (26\%). La distribución de las lesiones se presentó en forma clásica en 13 pacientes (43\%) y en forma atípica en 17 $(56 \%)$, ya sea en la topografía o en la morfología del cuadro. Catorce pacientes con la forma atípica en su topografía presentaron las lesiones en las extremidades superiores e inferiores; tres pacientes las presentaron en regiones axilares e inguinales_exclusivamente. Cinco pacientes presentaron pápulas, además de las placas eritematoescamosas; ningún paciente presentó formas atípicas con vesículas o manchas purpúricas en la clínica. De los 17 pacientes con formas atípicas en siete se corroboró el diagnóstico por biopsia de piel. Seis de estas biopsias presentaron los hallazgos característicos de pitiriasis rosada y un caso tuvo, además, el fenómeno purpúrico.

No se realizaron exámenes virales en ningún caso por considerar inconstante el reporte de casos en la literatura médica especializada. 


\section{DISCUSIÓN}

La pitiriasis rosada de Gibert es una entidad frecuente en nuestro hospital. Es infrecuente que el diagnóstico lo realice un médico de primer contacto por tratarse de una entidad poco conocida. La edad de presentación en nuestra población es similar a la reportada en la literatura internacional, sin predominio significativo por algún género. Las estaciones de mayor presentación del cuadro de pitiriasis rosada fueron otoño e invierno. La diferencia más importante en nuestro estudio es que la forma clásica se presentó en menos de la mitad de los casos (43\%), mientras que las formas atípicas fueron más frecuentes y raras en su presentación y topografía. Esto, probablemente se deba a que nuestro estudio se realizó en un hospital de tercer nivel al cual llegan casos especiales.

Debido a que la enfermedad se inicia con una lesión de forma ovalada con descamación fina en la periferia, que permanece aislada por ocho a diez días, los pacientes consultan hasta que observan la aparición rápida de las placas anulares en un periodo de una a dos semanas.

El diagnóstico correcto hecho por el médico de primer contacto es fundamental y evitará tratamientos innecesarios. La información completa de la entidad disminuye la preocupación de los padres al saber que es un cuadro benigno de duración prolongada, sin afección del estado general y no requiere exámenes de laboratorio. El prurito leve es el síntoma más frecuente. Así mismo, el tratamiento con eritromicina oral en su fase inicial puede reducir el tiempo de evolución.

Es importante mencionar que la pitiriasis rosada no es contagiosa y no es necesario aislar al paciente ni evitar que vaya a la escuela o que siga en contacto con el resto de la familia. Los pacientes deben evitar la exposición solar prolongada.

\section{REFERENCIAS}

1. Percival GH. Pityriasis rosea. Br J Dermatol 1932;44:241-53.

2. Chuang TY, Ilstrup DM, Perry HO, Kurland LT. Pityriasis rosea in Rochester, Minnesota 1969-78. J Am Acad Dermatol 1982;7:80-89.

3. Ozge G, Siebel E, Aysen K. Childhood Pityriasis Rosea. Ped Dermatol 2009;26:750-51.

4. González LM, Allen R, Janniger CK, Schwartz RA. Pityriasis rosea: An important papuloscamous disorder. Int J of Dermatol 2005;44;757-64.

5. Drago F, Broccolo F, Rebora A. Pityriasis rosea: An update with a critical appraisal of its possible herpes viral etiology. J Am Acad 2009;61(2):303-18.

6. Hendricks AA, Lohr JA. Pityriasis rosea in infancy. Arch Dermatol 1979;115:896-7.

7. Casani C. Pitiriasis Rosada Recurrente. Rev Pediatr Aten Primaria. 2006;8(6):15-9.

8. Rebora A, Drago F, Broccolo F. Pityriasis rosea and herpes viruses: Facts and controversies. Clin in Dematology 2010;28:497-501.

9. Kwon NH, Kim JE, Cho BK, Park HJ. A novel influenza a (H1N1) virus as a possible cause of pityriasis rosea? JEADV 2011;25:368-69.

10. Chuh AA, Chan HH. Prospective case-control study of Chlamydia, legionella and mycoplasma infections in patients with pityriasis rosea. Eur J Dermatol 2002;11:170-3.

11. Niles HD, Klumpp MM. Pityriasis rosea: Review of the literature and report of two hundred and nineteen cases, in thirty eight of which convalescent serum was used. Arch Dermatol Syphilol 1940;41:265-94.

12. Bjornberg A, Hellgren L. Pityriasis rosea: a statistical, clinical, and laboratory investigation of 826 patients and matched healthy controls. Acta Derm Venereol 1962;42(Suppl):1-68.

13. Wollenberg A, Eames T. Skin Diseases following a christmas tree pattern. Clin in Dermatology 2011;29:189-94.

14. Vidimos AT, Camisa C. Tongue and cheek: oral lesions in pityriasis rosea. Cutis 1992;50:276-80.

15. Ackerman AB. Histologic Diagnosis of inflammatory Skin Disease: a Method By Pattern Analysis. Philadelphia: 3rd edition; 1978:233-35.

16. Goens JL, Janniger CK, De Wolf K. Dermatologist and sytemic manifestations of syphilis. Am Fam Physician 1994;50:1013-1020.

17. Chuh AA, Dofitas BL, Comisel GG, Reveiz L, Sharma V, et al. Interventions for pityriasis rosea. Cochrane Database Syst Rev 2:CD005068 (2007).

18. Sharma PK, Yadav TP, Gautam RK, Taneja N, Satyanarayana L. Erythromicin in pityriasis rosea: a double-blind, placebocontrolled clinical trial. J Am Acad Dermatol 2000;42:241244. 